\title{
Imaging features and clinic value of mri and ct in diagnosis of clear cell renal cell carcinoma
}

\author{
Zhongjie YANG ${ }^{1 \star}\left(\mathbb{0}\right.$, Ming $\mathrm{LI}^{1}$, Aiju GUO ${ }^{1}$, Yonghui LIANG ${ }^{1}$, Peng FANG ${ }^{1}$
}

\begin{abstract}
To investigate the imaging features and clinic value of magnetic resonance imaging (MRI) and computed tomography (CT) in the diagnosis of clear cell renal cell carcinoma (ccRCC). 139 RCC patients underwent MRI and CT examination before surgery, and the sensitivity, specificity, accuracy, positive and negative predictive values of MRI and CT in diagnosing ccRCC were analyzed and compared. There were 93 true-positive, 11 false-positive, 11 false-negative and 24 true-negative in MRI screening with sensitivity, specificity, accuracy, positive predictive value and negative predictive value of $89.42 \%, 68.57 \%, 84.17 \%, 89.42 \%$ and $68.57 \%$ respectively. Whereas there were 72 true-positive, 4 false-positive, 32 false-negative and 31 true-negative in CT screening with the sensitivity, specificity, accuracy, positive predictive value and negative predictive value of $69.23 \%, 88.57 \%$, $74.10 \%, 94.74 \%$ and $49.21 \%$ respectively. The sensitivity and negative predictive value of MRI were better than those of CT, while the specificity of CT was better than that of MRI. MRI and CT have respective advantages in the diagnosis of ccRCC. The sensitivity and negative predictive value of MRI are superior to those of CT, while the specificity of CT is superior to that of MRI. Clinically, different examinations are selected according to different situations.
\end{abstract}

Keywords: MRI; CT; clear cell renal cell carcinoma; imaging features; diagnostic value.

Practical Application: The diagnostic value of MRI and CT in ccRCC.

\section{Introduction}

Renal cancer accounts for $5 \%$ and $3 \%$ of all malignant tumors in men and women respectively, being the 7th most common cancer in men and the 10th in women (Siegel et al., 2017). Renal cell carcinoma (RCC) is a cancer originating from renal epithelium, accounting for more than $90 \%$ of cancers in the kidney, and about $30 \%$ of patients have metastatic diseases at the time of diagnosis (Ferlay et al., 2015). It includes more than 10 histological and molecular subtypes, of which clear cell RCC (ccRCC) is the most common and the leading cause of death (Hsieh et al., 2017) with a 5-year survival rate of 68.9\% (Cheville et al., 2003). It has been reported that different subtypes of RCC have different prognosis and biological behavior due to their different genetic and histological features, and the prognosis of ccRCC is the worst among subtypes (Roy et al., 2007; Kim et al., 2002). Different subtypes should be treated differently, but improper interpretation of images can lead to misdiagnosis (Hu et al., 2014). Therefore, radiologists are familiar with the imaging appearance of RCC, and understand that the subtype of RCC is important for the treatment and prognosis of patients.

With the continuous development of imaging technology, it is particularly important to be familiar with the characteristics and advantages of various imaging examinations. Choosing appropriate imaging methods according to the pathological conditions of patients plays a vital role in the diagnosis of RCC, which determines the early diagnosis efficiency of tumors, and is also essential for tumor staging and treatment plan (Catalano et al., 2003; Vargas et al., 2012). At present, magnetic resonance imaging (MRI) and computed tomography (CT) are the most commonly used imaging methods in clinical diagnosis of RCC. CT scans evaluates local invasiveness, lymph node involvement or distant metastasis, and MRI provides additional information on local progress of tumor thrombus and vein involvement. In order to determine the stage of RCC, it is very necessary to perform enhanced chest, abdomen and pelvic CT. However, if patients are allergic to CT contrast agents, chest high-resolution CT scans and abdominal MRI without contrast agents should be performed (Escudier et al., 2019; Koshani et al., 2020). MRI is usually used as a supplement to CT because of its high cost, long scanning time and patients' contraindication.

Most of the relevant literature on the diagnostic value of imaging are based on imaging analysis and comparison, so this study aims to compare the diagnostic value of CT and MRI in ccRCC in terms of sensitivity, specificity, accuracy, positive predictive value and negative predictive value. 


\section{Materials and methods}

\subsection{General data}

139 RCC patients admitted to Henan Province Hospital of TCM from July 2015 to December 2017 were selected and retrospectively analyzed, with an average age of $(45.46 \pm 15.18)$. Among them, 104 were confirmed as ccRCC by biopsy or pathology, including 68 males and 36 females, with the main clinical symptoms of gross hematuria, waist soreness and abdominal pain, and some patients with mild anemia after laboratory examination. Inclusion criteria: patients receiving no interventional therapy or relevant kidney surgery before CT and MRI; patients with comprehensive and accurate hospitalization records, pathology and operation records. Exclusion criteria: patients allergic to CT and MRI contrast agents and hypotonic drugs; patients in pregnancy, lactation or with blood system diseases, abdominal surgery history and other tumors and metastases. This study was approved by the Medical Ethics Committee, and all subjects signed informed consent forms. General information of patients is shown in Table 1.

\subsection{Instruments}

Discovery CT750HD and Signal HDXT 3.0T MRI apparatus were both purchased from GE Company; Iohexol contrast agent was

Table 1. General information of patients.

\begin{tabular}{|c|c|c|c|}
\hline Factor & & $\mathbf{n}$ & Rate (\%) \\
\hline \multicolumn{4}{|l|}{ Age (year) } \\
\hline & $\geq 45$ & 99 & 71.22 \\
\hline & $<45$ & 40 & 28.78 \\
\hline \multicolumn{4}{|l|}{ Gender } \\
\hline & Male & 82 & 58.99 \\
\hline & Female & 57 & 41.01 \\
\hline \multicolumn{4}{|c|}{ Onset of symptom (month) } \\
\hline & $\geq 3$ & 62 & 44.60 \\
\hline & $<3$ & 77 & 55.40 \\
\hline \multicolumn{4}{|c|}{ Tumor size $(\mathrm{cm})$} \\
\hline & $\geq 3$ & 65 & 46.76 \\
\hline & $<3$ & 74 & 53.24 \\
\hline \multicolumn{4}{|c|}{ Clinical stage } \\
\hline & $\mathrm{I}+\mathrm{II}$ & 89 & 64.03 \\
\hline & III+IV & 50 & 35.97 \\
\hline \multicolumn{4}{|c|}{ Lymphatic metastasis } \\
\hline & Yes & 37 & 26.62 \\
\hline & No & 102 & 73.38 \\
\hline \multicolumn{4}{|c|}{ Distant metastasis } \\
\hline & Yes & 14 & 10.07 \\
\hline & No & 125 & 89.93 \\
\hline \multicolumn{4}{|c|}{ Tumor distribution } \\
\hline & Left kidney & 76 & 54.68 \\
\hline & Right kidney & 63 & 45.32 \\
\hline
\end{tabular}

purchased from Guangzhou Xianling Company; gadolinium-DTPA (GD-DTPA) contrast agent was purchased from GE Company.

\subsection{MRI examination}

Fasted for 6- $8 \mathrm{~h}$ before scanning, the patients were examined by plain and enhanced scans in a horizotntal position after inhalation. Axial spin-echo (SE) sequence T1 weighted image (WI), T2 WI, diffusion weighted image (DWI), gradient echo in-phase (IP) and opposed-phase (OP) and fast volumetric plain scan were used for onventional examination, with a scanning layer thickness of $6 \mathrm{~mm}$. Gd-DTPA (15-30 mL) was used as the contrast agent in enhanced scanning and was then injected into forearm superficial vein with a high-pressure syringe at $2.5 \mathrm{~mL} / \mathrm{s}$. The scanning was performed for 30 seconds in arterial phase and 240 seconds in excretory phase.

\subsection{CT examination}

The patients fasted for more than 8 hours before examination, 800-1000 mL of warm water was taken to fill the intestinal tract 30 min before scanning, and the scanning was started after inhalation. The patients lied on a scanning bed in a horizotntal position, then the scanning parameters were set: tube voltage 120-140 Kv, tube current 220-260 mAs, pitch 1-1.5, bed moving speed $5-10 \mathrm{~mm} / \mathrm{s}$, slice thickness $5-7 \mathrm{~mm}$, reconstruction interval 1-2 mm, and interlayer distance 2.5-3.5 mm. Enhanced scan was performed after plain scan using 70-100 mL of iohexol contrast agent $(300 \mathrm{mgI} / \mathrm{mL})$ injection at $3 \mathrm{~mL} / \mathrm{s}$. The scan was performed for 25-30 seconds in arterial phase, 60-90 in nephpographic phase, and 180-300 in excretory phase.

\subsection{Diagnostic analysis}

Imaging analysis was performed by two radiologists with more than 10 years of experience, and the patients were confirmed with renal cell carcinoma according to the results combined with pathological characteristics. The typical ccRCC manifests a significant enhancement in the cortex, medulla and kidney imaging stages, with a relatively low density in the parenchymal phase, which is a fast-forward, fast-out enhancement. Pathological gold standard results were used as a control for the diagnostic efficacy of the two imaging methods, and the sensitivity, specificity, accuracy, positive predictive value and negative predictive value were used as evaluation indicators.

\subsection{Statistical analysis}

SPSS 20.0 (Shanghai Cabit Information Technology Co., Ltd.) statistical software was used for analysis. McNemar test was used for counting data, and $P<0.05$ indicated statistical significance.

\section{Results}

\subsection{MRI imaging analysis of $c c R C C$}

MRI showed that lesions appeared hypointense on TIWI and hyperintense on $\mathrm{T} 2 \mathrm{Wl}$ in ccRCC, most of which showed peripheral enhancement, and whole-tumor showed uneven enhancement. CT showed that the tumors had equal, slightly lower or slightly higher density than surrounding renal tissue in ccRCC, with 
inhomogeneous or mixed density and uneven enhancement, which was significantly enhanced in the corticomedullary phase, as shown in Figures 1-4.

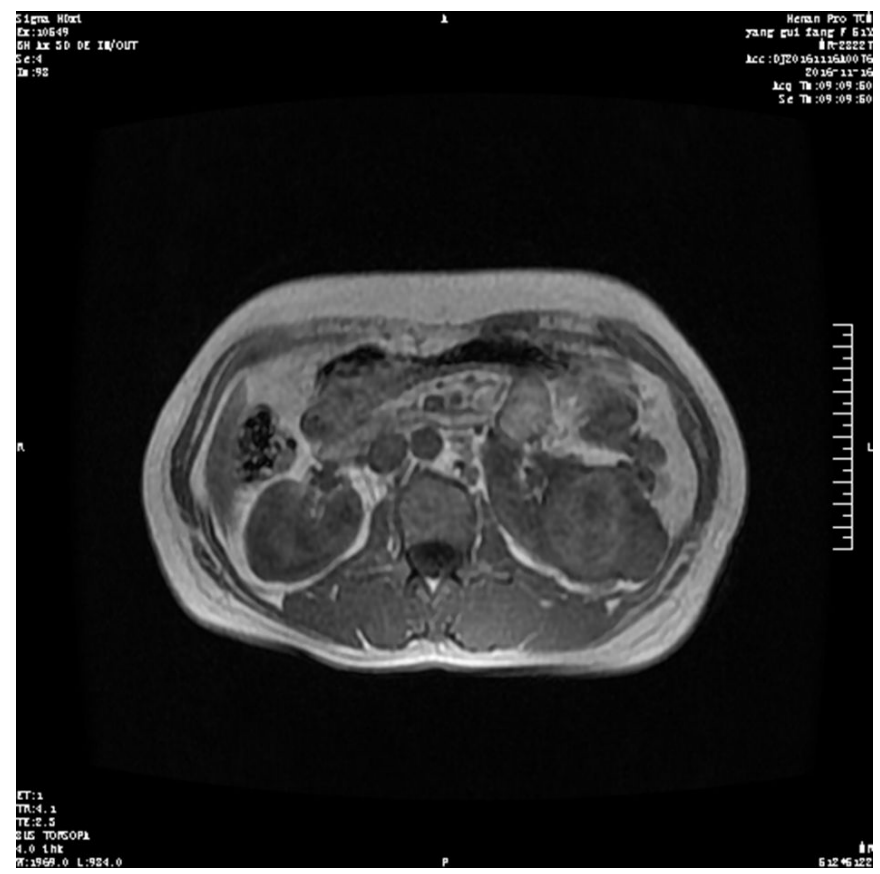

Figure 1. Chromophobe cell carcinoma. There were T1 WI, T2 WI, early and late enhanced MRI images respectively. The lesions were round-like and well-defined with equal-signal on T1 WI, equal and slightly lower on T2 WI. Uneven enhancement showed at the early stage of enhanced scan then slightly decreased at the late stage.

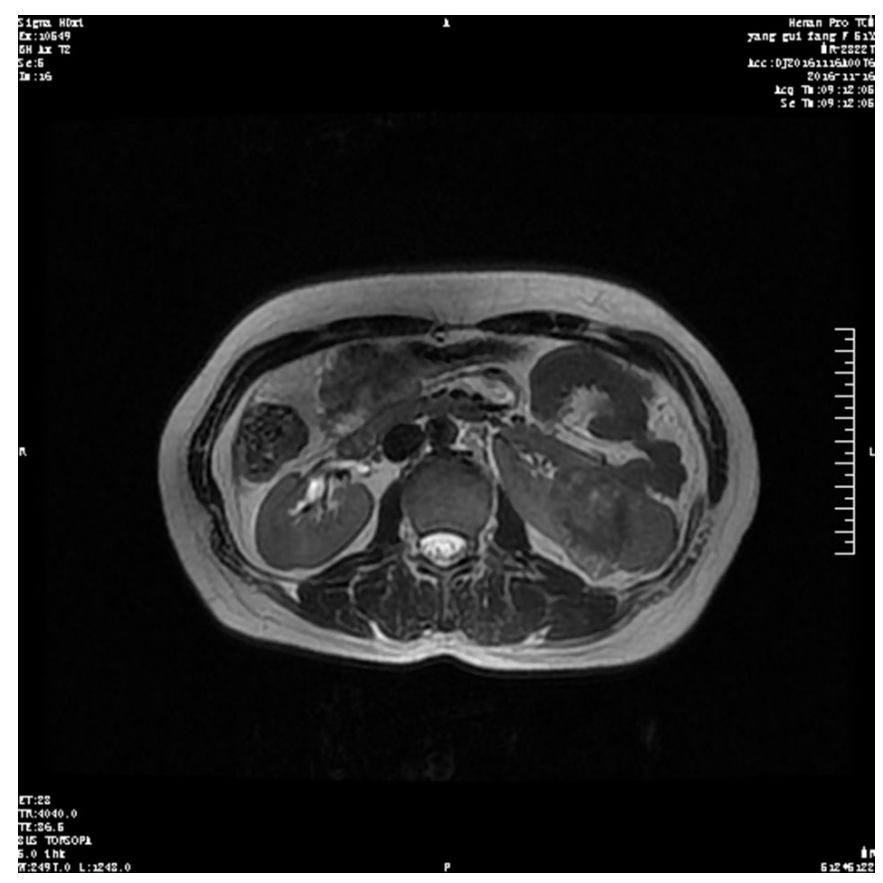

Figure 2. Sarcomatoid renal carcinoma. Massive round-like masses can be seen. The masses were massive round-like with equal-signal on T1 $\mathrm{WI}$, equal and slightly higher on T2 WI, and delayed and progressive enhancement showed with mainly banding-like peripheral enhancement.

\subsection{Comparison of MRI and CT in the diagnosis of ccRCC}

There were 93 true-positive, 11 false-positive, 11 false-negative and 24 true-negative in MRI screening. And the sensitivity was $89.42 \%$ (93/104), specificity was $68.57 \%$ (24/35), accuracy was

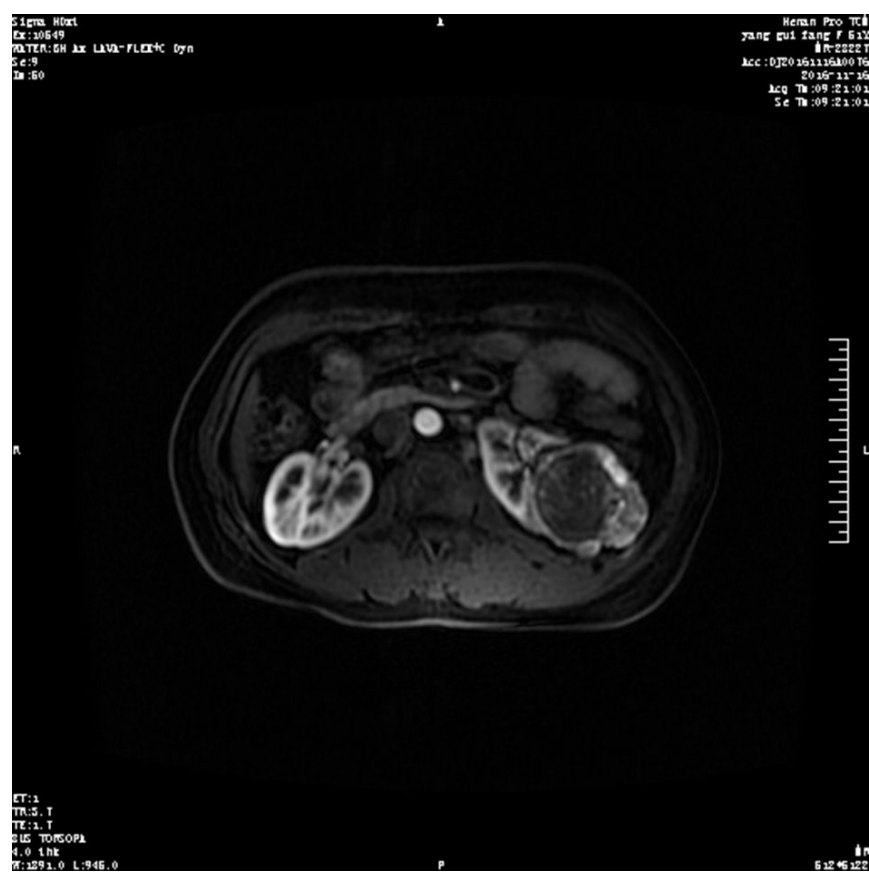

Figure 3. Mucinous tubule and spindle renal cell carcinoma. Round-like masses can be seen in the cortex with low-signal on T1 WI, high-signal on T2 WI, and no enhancement in early stage but delayed mild enhancement in late stage.

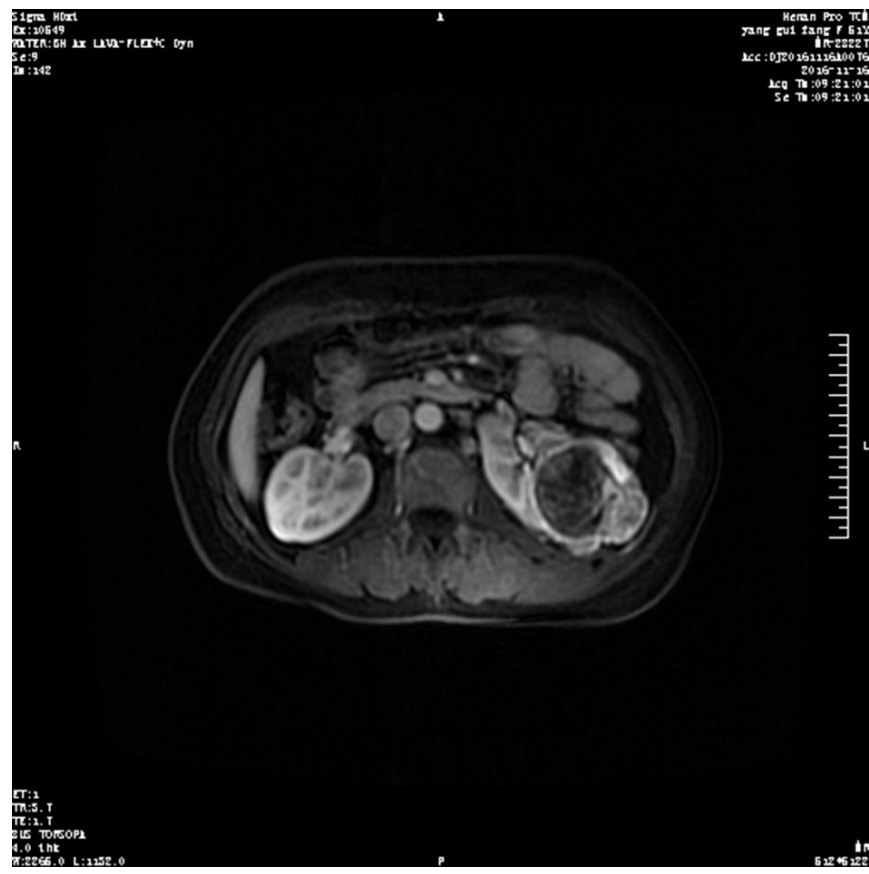

Figure 4. XP11. 2 translocation/TFE3 gene fusion related renal carcinoma. CT plain scan and CT enhanced image respectively. Solid masses with dot high density shadows and slight enhancement. 
$84.17 \%((93+24) / 139)$, positive predictive value was $89.42 \%$ $(93 / 104)$, and negative predictive value was $68.57 \%(24 / 35)$.

There were 72 true-positive, 4 false-positive, 32 false-negative and 31 true-negative in CT screening. And the sensitivity was $69.23 \%$ (72/104), specificity was $88.57 \%$ (31/35), accuracy was $74.10 \%((72+31) / 139)$, positive predictive value was $94.74 \%$ (72/76), and negative predictive value was $49.21 \%(31 / 63)$.

There was no significant difference in positive predictive value and accuracy between MRI and CT screening $(P>0.05)$. The sensitivity and negative predictive value of MRI were better than those of CT, while the specificity of CT was better than that of MRI $(P<0.05)$. See Tables $2-4$ for details.

\section{Discussion}

RCC, the most deadly malignant tumor of urinary system (Motzer et al., 2011; Siegel et al., 2015; Wu et al., 2020), is not a single entity, but heterogeneous tumors with different histological findings, cytogenetic abnormalities, biological behavior, prognosis and therapeutic response (LopezBeltran et al., 2009). The RCC was classified into several different subtypes by Adult Renal Tumors Classification of World Health Organization in 2004, of which ccRCC accounts for $70 \%$. Due to its rich lipid content, ccRCC was golden on cut specimens, while alveoli, acinus or solid structures, including clear or eosinophilic cytoplasm and fine vascular network, were usually detected by micro-testings (Ramankulov et al., 2008). Compared with other subtypes, ccRCC develops symptoms in the late stage and has a poorer prognosis and a

Table 2. Comparison of MRI results and pathological results.

\begin{tabular}{lccc}
\hline \multirow{2}{*}{ MRI } & \multicolumn{2}{c}{ Pathological result } & \multirow{2}{*}{ Total } \\
\cline { 2 - 3 } & ccRCC & Other subtype & \\
\hline ccRCC & 93 & 11 & 104 \\
Other subtype & 11 & 24 & 35 \\
Total & 104 & 35 & 139 \\
\hline
\end{tabular}

Table 3. Comparison of CT results and pathological results.

\begin{tabular}{lccc}
\hline \multirow{2}{*}{ CT } & \multicolumn{2}{c}{ Pathological result } & \multirow{2}{*}{ Total } \\
\cline { 2 - 3 } & ccRCC & Other subtype & \\
\hline ccRCC & 72 & 4 & 76 \\
Other subtype & 32 & 31 & 63 \\
Total & 104 & 35 & 139 \\
\hline
\end{tabular}

greater tendency to metastasize, with a metastatic rate of $94 \%$ (Amin et al., 2002; Young et al., 2013). The most common sites for metastasis are different according to subtypes, and lung is the most common site for ccRCC metastasis (Hoffmann et al., 2008; Gurel et al., 2013). Imaging is still the main basis for RCC diagnosis, screening, follow-up and treatment monitoring. Researches show that ccRCC subtypes can be non-invasively distinguished in imaging (Sun et al., 2009; Prasad et al., 2006).

Taking pathological diagnosis as the gold standard, the diagnostic values of MRI and CT were compared, and the imaging features of MRI in diagnosing ccRCC were analyzed in our study. The results showed that there were 97 true-positive, 7 false-positive, 5 false-negative and 30 true-negative in MRI screening with the sensitivity, specificity, accuracy, positive predictive value and negative predictive value of $95.10 \%, 81.08 \%$, $91.37 \%, 93.27 \%$ and $85.71 \%$ respectively. Whereas there were 88 true-positive, 16 false-positive, 10 false-negative and 25 true-negative in CT screening with the sensitivity, specificity, accuracy, positive predictive value and negative predictive value of $89.80 \%, 60.98 \%, 81.29 \%, 84.62 \%$ and $71.43 \%$ respectively. There was no significant difference in positive predictive value and accuracy between MRI and CT screening $(P>0.05)$. The sensitivity and negative predictive value of MRI were better than those of CT, while the specificity of CT was better than that of MRI $(P<0.05)$. Therefore, MRI is better than CT in diagnosing ccRCC. The reason may be that a small number of ccRCC have uncertain enhancements when using CT scan, and heterogeneity, irregular margin and calcification are suggestive diagnostic features. However, quantitative and qualitative contrast-enhanced (CE)-MRI can distinguish ccRCC accurately (Beddy et al., 2014; Wang et al., 2017).

The images in our study showed that MRI features of ccRCC lesions were hypointense on TIWI and hyperintense on T2Wl, most of which showed peripheral enhancement, and the wholetumor showed uneven enhancement. CT features of ccRCC tumors had equal, slightly lower or slightly higher density than surrounding renal tissues, with inhomogeneous or mixed density and uneven enhancement, which was significantly enhanced in the corticomedullary phase. According to relevant studies, the general morphological characteristics of CCRC indicate its subtypes. The typical manifestation of CCRCs is exogenous growth, with heterogeneity tendency due to intratumoral necrosis, cystic changes or hemorrhage (Prasad et al., 2006; Low et al., 2016), which are consistent with the MRI imaging features described in our study. In addition, Pedrosa et al. (2008) found that the large volume, intratumoral necrosis, retroperitoneal vascular collaterals and renal vein thrombosis predicted high-stage clear cell subtype.

Table 4. Comparison of the efficacy of MRI and CT in the diagnosis of ccRCC (\%).

\begin{tabular}{|c|c|c|c|c|c|c|}
\hline Group & $\mathbf{n}$ & Sensitivity & Specificity & Accuracy & $\begin{array}{c}\text { Positive predictive } \\
\text { value }\end{array}$ & $\begin{array}{c}\text { Negative predictive } \\
\text { value }\end{array}$ \\
\hline MRI & 139 & 89.42 & 68.57 & 84.17 & 89.42 & 68.57 \\
\hline CT & 139 & 69.23 & 88.57 & 74.10 & 94.74 & 49.21 \\
\hline $\mathrm{Z}$ test & & 3.47 & 3.27 & 1.74 & 1.56 & 2.88 \\
\hline Pvalue & & 0.00 & 0.00 & 0.08 & 0.12 & 0.01 \\
\hline
\end{tabular}


Karlo et al. (2013) found that a decrease in signal intensity on opposed-phase chemical shift images was not an identifying feature of ccRCCs, but can also be observed in angiomyolipoma and other subtypes of RCC. After excluding angiomyolipomas, a decrease in signal intensity of more than $25 \%$ was diagnostic for ccRCCs. An important imaging feature of MRI is the signal intensity appearance of tumors on T2 WI, and most ccRCCs show high T2 signal intensity (Low et al., 2016). Sun et al. (2009) evaluated the T1 and T2 signal intensities of 49 RCC patients, including $28 \mathrm{ccRCCs}$ and 21 papillary RCCs, and it was found that although the T1 signal intensity of the two subtypes were similar, it can be distinguished according to T2 signal intensity. Papillary RCCs showed an average signal intensity ratio of $0.67 \pm 0.2$, and ccRCC showed $1.41 \pm 0.4(P<0.05)$. A multiphase MRI study on 113 renal masses conducted by Oliva et al. (2009) found that ccRCC had significantly higher signal intensity changes in cortical medulla and renal phases than other subtypes. ccRCC also had higher tumor-cortical enhancement index (TCR) than other subtypes in these two phases.

\section{Conclusions}

To sum up, the diagnostic efficiency of MRI scan screening in ccRCC is better than that of CT. MRI can provide a more detailed imaging basis when CT scan screening is not sufficient to accurately determine ccRCC lesions. Therefore, MRI is a screening method and an important basis for providing reasonable treatment in the affordable range.

\section{References}

Amin, M. B., Amin, M. B., Tamboli, P., Javidan, J., Stricker, H., Venturina, M. D.-P., Deshpande, A., \& Menon, M. (2002). Prognostic impact of histologic subtyping of adult renal epithelial neoplasms: an experience of 405 cases. The American Journal of Surgical Pathology, 26(3), 281-291. http://dx.doi.org/10.1097/00000478-20020300000001. PMid:11859199.

Beddy, P., Genega, E. M., Ngo, L., Hindman, N., Wei, J., Bullock, A., Bhatt, R. S., Atkins, M. B., \& Pedrosa, I. (2014). Tumor necrosis on magnetic resonance imaging correlates with aggressive histology and disease progression in clear cell renal cell carcinoma. Clinical Genitourinary Cancer, 12(1), 55-62. http://dx.doi.org/10.1016/j. clgc.2013.07.006. PMid:24145001.

Catalano, C., Fraioli, F., Laghi, A., Napoli, A., Pediconi, F., Danti, M., Nardis, P., \& Passariello, R. (2003). High-resolution multidetector $\mathrm{CT}$ in the preoperative evaluation of patients with renal cell carcinoma. American Journal of Roentgenology, 180(5), 1271-1277. http://dx.doi.org/10.2214/ajr.180.5.1801271. PMid:12704036.

Cheville, J. C., Lohse, C. M., Zincke, H., Weaver, A. L., \& Blute, M. L. (2003). Comparisons of outcome and prognostic features among histologic subtypes of renal cell carcinoma. The American Journal of Surgical Pathology, 27(5), 612-624. http://dx.doi.org/10.1097/00000478200305000-00005. PMid:12717246.

Escudier, B., Porta, C., Schmidinger, M., Rioux-Leclercq, N., Bex, A., Khoo, V., Grünwald, V., Gillessen, S., \& Horwich, A. (2019). Renal cell carcinoma: ESMO Clinical Practice Guidelines for diagnosis, treatment and follow-up. Annals of Oncology, 30(5), 706-720. http://dx.doi.org/10.1093/annonc/mdz056. PMid:30788497.

Ferlay, J., Soerjomataram, I., Dikshit, R., Eser, S., Mathers, C., Rebelo, M., Parkin, D. M., Forman, D., \& Bray, F. (2015). Cancer incidence and mortality worldwide: sources, methods and major patterns in GLOBOCAN 2012. International Journal of Cancer, 136(5), E359-E386. http://dx.doi.org/10.1002/ijc.29210. PMid:25220842.

Gurel, S., Narra, V., Elsayes, K. M., Siegel, C. L., Chen, Z. E., \& Brown, J. J. (2013). Subtypes of renal cell carcinoma: MRI and pathological features. Diagnostic and Interventional Radiology, 19(4), 304-311. http://dx.doi.org/10.5152/dir.2013.147. PMid:23439256.

Hoffmann, N. E., Gillett, M. D., Cheville, J. C., Lohse, C. M., Leibovich, B. C., \& Blute, M. L. (2008). Differences in organ system of distant metastasis by renal cell carcinoma subtype. The Journal of Urology, 179(2), 474-477. http://dx.doi.org/10.1016/j.juro.2007.09.036. PMid:18076920.

Hsieh, J. J., Purdue, M. P., Signoretti, S., Swanton, C., Albiges, L., Schmidinger, M., Heng, D. Y., Larkin, J., \& Ficarra, V. (2017). Renal cell carcinoma. Nature Reviews. Disease Primers, 3(1), 17009. http://dx.doi.org/10.1038/nrdp.2017.9. PMid:28276433.

Hu, H. Y., Wei, S. P., \& Zhang, Z. J. (2014). Application of combined conventional two-dimensional ultrasound and contrast-enhanced ultrasound in differentiating subtypes of renal cell carcinoma. Jiangsu Medical Journal, 40, 1566-1569.

Karlo, C. A., Donati, O. F., Burger, I. A., Zheng, J., Moskowitz, C. S., Hricak, H., \& Akin, O. (2013). MR imaging of renal cortical tumours: qualitative and quantitative chemical shift imaging parameters. European Radiology, 23(6), 1738-1744. http://dx.doi.org/10.1007/ s00330-012-2758-x. PMid:23300041.

Kim, J. K., Kim, T. K., Ahn, H. J., Kim, C. S., Kim, K. R., \& Cho, K. S. (2002). Differentiation of subtypes of renal cell carcinoma on helical CT scans. AJR. American Journal of Roentgenology, 178(6), 14991506. http://dx.doi.org/10.2214/ajr.178.6.1781499. PMid:12034628.

Koshani, R., Jafari, S. M., \& van de Ven, T. G. M. (2020). Going deep inside bioactive-loaded nanocarriers through Nuclear Magnetic Resonance (NMR) spectroscopy. Trends in Food Science \& Technology, 101, 198-212. http://dx.doi.org/10.1016/j.tifs.2020.05.010.

Lopez-Beltran, A., Carrasco, J. C., Cheng, L., Scarpelli, M., Kirkali, Z., \& Montironi, R. (2009). 2009 update on the classification of renal epithelial tumors in adults. International Journal of Urology, 16(5), 432-443. http://dx.doi.org/10.1111/j.1442-2042.2009.02302.x. PMid:19453547.

Low, G., Huang, G., Fu, W., Moloo, Z., \& Girgis, S. (2016). Review of renal cell carcinoma and its common subtypes in radiology. World Journal of Radiology, 8(5), 484-500. http://dx.doi.org/10.4329/wjr. v8.i5.484. PMid:27247714.

Motzer, R. J., Agarwal, N., Beard, C., Bhayani, S., Bolger, G. B., Carducci, M. A., Chang, S. S., Choueiri, T. K., Hancock, S. L., Hudes, G. R., Jonasch, E., Josephson, D., Kuzel, T. M., Levine, E. G., Lin, D. W., Margolin, K. A., Michaelson, M. D., Olencki, T., Pili, R., Ratliff, T. W., Redman, B. G., Robertson, C. N., Ryan, C. J., Sheinfeld, J., Spiess, P. E., Wang, J., \& Wilder, R. B. (2011). Kidney cancer. Journal of the National Comprehensive Cancer Network, 9(9), 960977. http://dx.doi.org/10.6004/jnccn.2011.0082. PMid:21917622.

Oliva, M. R., Glickman, J. N., Zou, K. H., Teo, S. Y., Mortelé, K. J., Rocha, M. S., \& Silverman, S. G. (2009). Renal cell carcinoma: $t 1$ and t2 signal intensity characteristics of papillary and clear cell types correlated with pathology. AJR. American Journal of Roentgenology, 192(6), 1524-1530. http://dx.doi.org/10.2214/AJR.08.1727. PMid:19457814.

Pedrosa, I., Chou, M. T., Ngo, L., H Baroni, R., Genega, E. M., Galaburda, L., DeWolf, W. C., \& Rofsky, N. M. (2008). MR classification of renal masses with pathologic correlation. European Radiology, 18(2), 365375. http://dx.doi.org/10.1007/s00330-007-0757-0. PMid:17899106.

Prasad, S. R., Humphrey, P. A., Catena, J. R., Narra, V. R., Srigley, J. R., Cortez, A. D., Dalrymple, N. C., \& Chintapalli, K. N. (2006). 
Common and uncommon histologic subtypes of renal cell carcinoma: imaging spectrum with pathologic correlation. Radiographics, 26(6), 1795-1806. http://dx.doi.org/10.1148/rg.266065010.

Ramankulov, A., Lein, M., Johannsen, M., Schrader, M., Miller, K., Loening, S. A., \& Jung, K. (2008). Serum amyloid A as indicator of distant metastases but not as early tumor marker in patients with renal cell carcinoma. Cancer Letters, 269(1), 85-92. http://dx.doi.org/10.1016/j.canlet.2008.04.022. PMid:18504068.

Roy, C., Sauer, B., Lindner, V., Lang, H., Saussine, C., \& Jacqmin, D. (2007). MR Imaging of papillary renal neoplasms: potential application for characterization of small renal masses. European Radiology, 17(1), 193200. http://dx.doi.org/10.1007/s00330-006-0271-9. PMid:16758161.

Siegel, R. L., Miller, K. D., \& Jemal, A. (2015). Cancer statistics, 2015. CA: a Cancer Journal for Clinicians, 65(1), 5-29. http://dx.doi.org/10.3322/caac.21254. PMid:25559415.

Siegel, R. L., Miller, K. D., \& Jemal, A. (2017). Cancer statistics, 2017. CA: a Cancer Journal for Clinicians, 67(1), 7-30. http://dx.doi.org/10.3322/caac.21387. PMid:28055103.

Sun, M. R., Ngo, L., Genega, E. M., Atkins, M. B., Finn, M. E., Rofsky, N. M., \& Pedrosa, I. (2009). Renal cell carcinoma: dynamic contrastenhanced MR imaging for differentiation of tumor subtypes-correlation with pathologic findings. Radiology, 250(3), 793-802. http://dx.doi.org/10.1148/radiol.2503080995. PMid:19244046.
Vargas, H. A., Chaim, J., Lefkowitz, R. A., Lakhman, Y., Zheng, J., Moskowitz, C. S., Sohn, M. J., Schwartz, L. H., Russo, P., \& Akin, O. (2012). Renal cortical tumors: use of multiphasic contrast-enhanced MR imaging to differentiate benign and malignant histologic subtypes. Radiology, 264(3), 779-788. http://dx.doi.org/10.1148/radiol.12110746. PMid:22829683.

Wang, H. Y., Su, Z. H., Xu, X., Huang, N., Sun, Z. P., Wang, Y. W., Li, L., Guo, A. T., Chen, X., Ma, X., Ma, L., \& Ye, H. Y. (2017). Dynamic contrast-enhanced MRI in renal tumors: common subtype differentiation using pharmacokinetics. Scientific Reports, 7(1), 3117. http://dx.doi.org/10.1038/s41598-017-03376-7. PMid:28596583.

Wu, X., Li, M., Xiao, Z., Daglia, M., Dragan, S., Delmas, D., Vong, C. T., Wang, Y., Zhao, Y., Shen, J., Nabavi, S. M., Sureda, A., Cao, H., Simal-Gandara, J., Wang, M., Sun, C., Wang, S., \& Xiao, J. (2020). Dietary polyphenols for managing cancers: what have we ignored? Trends in Food Science \& Technology, 101, 150-164. http://dx.doi.org/10.1016/j.tifs.2020.05.017.

Young, J. R., Margolis, D., Sauk, S., Pantuck, A. J., Sayre, J., \& Raman, S. S. (2013). Clear cell renal cell carcinoma: discrimination from other renal cell carcinoma subtypes and oncocytoma at multiphasic multidetector CT. Radiology, 267(2), 444-453. http://dx.doi.org/10.1148/radiol.13112617. PMid:23382290. 